\title{
Integration of Climate Change into the Namibian School Geography Curriculum
}

\section{Sirkka A.N. Tshiningayamwe}

\begin{abstract}
Of the various subjects taught in Namibian schools, Geography is often perceived as one that can make a significant contribution to climate change education. Despite this, there is a dearth of research on climate change integration into the Namibian school Geography curriculum. This paper, therefore, aims to explore the integration of climate change content into the Namibian school Geography curriculum. The paper analyses the Namibian school Geography curriculum and draws on four semi-structured interviews with Geography teachers. Shulman's concept of Pedagogical Content Knowledge was used to analyse the data. The analysis shows that climate change content is not yet fully integrated into the Namibian school Geography curriculum. Elements of climate change are integrated in the Geography curriculum; however the teachers experience conceptual challenges in integrating this content in their teaching. This is due to their lack of pedagogical content knowledge, lack of professional development support and inadequate quality teaching resources on climate change. The paper recommends more coverage of climate change concepts into the Geography curriculum and professional development for teachers on climate change education. This has the potential to provide secondary school learners with the knowledge on climate change which can help mitigate the impacts of climate change in Namibia.
\end{abstract}

Keywords: Climate change, Geography curriculum, Education for Sustainable Development (ESD) 


\section{Introduction}

In recent decades there has been evidence that changes in climate have caused impacts on natural and human systems on all continents. Climate change is a result of human activities such as agriculture, mining and processing industries (UNESCO 2015; UNEP 2016). 'Climate change is also caused by natural phenomena, which includes solar output, variations in the earth's orbit, volcanisms, ocean vacations, etc.' (Ozor 2006: 21). Some of the climate change impacts have been linked to human influences, including a decrease in cold temperature extremes, increase in warm temperature extremes and an increase in high sea levels (Ozor 2006; UNESCO 2015). Impacts from recent climate-related extremes, such as heat waves, droughts, floods and cyclones reveal significant vulnerability and exposure of some ecosystems and many human systems to current climate variability. The Fifth Intergovernmental Panel on Climate Change (IPCC) assessment report (2014) has revealed that further emissions of greenhouse gases will cause further warming and longterm effects in all components of the climate system, increasing the likelihood of severe, pervasive and irreversible impacts for people and ecosystems. This effect will be more prevalent in Southern Africa (UNEP 2016). Namibia is one of the countries in southern Africa whose vulnerability to climate change includes an increase in sea-level, droughts, floods, and possibly down-welling in the Atlantic Ocean (Namibia Ministry of Environment and Tourism 2011).

The IPCC (2014) assessment report warned the global community that urgent action is required to halt the worst effects of global climate change. There is a need to view both adaptation and mitigation within a wider framework of climate-resilient development pathways to realise the goals of sustainable development (IPCC 2014). This requires climate change education in all sectors of education (UNESCO 2015). Climate change mitigation requires education geared towards learning how to change lifestyles, economies and social structures that are based on excessive greenhouse gases production (IPCC 2014). Education can show people that, as conscious consumers and responsible citizens, they have a critical role to play in changing their lifestyles to address the current sustainability issues that humanity is facing (UNESCO 2015). In addition to education's integral role in individual behaviour change for mitigation, learning centres and schools have a role to play in mitigation in terms of becoming carbon neutral and energy efficient and reducing their own ecological footprint (Anderson 2012). 
Nhamo and Shava (2014) note that learning; associated education processes and curricula need to be a central part of establishing climateresilient pathways in southern Africa. There is some urgency to this, as Africa has been identified as a region highly vulnerable to the effects of climate change (IPCC 2014). ESD has been highlighted as important to reducing climate change actions (Urquhart et al. 2014; UNESCO 2015; UNEP 2016). This is key to the attainment of Sustainable Development Goal 13 that calls for taking urgent action to combat climate change and its impacts. Southern Africa has a long and rich history of environmental and sustainability education. Such education aims at offering learners the relevant knowledge, values, skills, strength, creativity and action competencies for the future (Lotz-Sisitka et al. 2017). This has been integrated in the countries' education agenda. In the Namibian context, the National Institute for Educational Development (NIED), which is the curriculum development institution in Namibia, has also made great strides to infuse environmental themes such as climate change in basic education systems.

Research has been conducted in southern Africa on the integration and implementation of ESD in the school curricula. The research by Lotz-Sisitka et al. (2017) focused on pedagogical approaches for ESD content in the school curricula. The subject of climate change is relatively new in the southern African school system, and consequently, learners and the general community have a limited understanding of the phenomenon (Urquhart et al. 2014; Anyanwu et al. 2015; Dlamini 2016). Nhamo and Shava conducted an audit in 2014 on how climate change education was being addressed in southern African countries across the different education levels as well as in the informal sector. This project complements other studies conducted in southern Africa and the UNESCO national case studies on climate change education (Urquhart et al. 2014; Anyanwu et al. 2015; Dlamini 2016). From the different research studies done, it is clear that climate change education is not yet fully integrated into the school curriculum in the southern African region. There is a constant demand for further research on the integration of climate change education and curriculum innovation at all education levels (Nhamo \& Shava 2014; Anyanwu et al. 2015; Dlamini 2016) - a topic which this paper addresses from the context of the Namibian school Geography curriculum. Geography is one of the subjects offered in the Namibian school Geography curriculum and is described as 'both a powerful medium for promoting the education of individuals as well as a major contributor to international, environmental and 
development' (Ekpoh 2009: 98). Dube (2017) argued that ESD (including climate change) can be implemented effectively through the Geography curriculum because the subject is interdisciplinary and deals with human environment interactions. Integration of climate change education into the school curriculum is within the on-going trajectory of the Global Action Plan for Education for Sustainable Development, which is set to take the work of the United Nations Decade of ESD forward at national and global levels. The paper thus focused on how climate change content is integrated into the Namibian school Geography curriculum, and what challenges the integration of climate change content in the Namibian school Geography curriculum pose.

\section{Climate Change Education in the Global Context}

Addressing climate change is now one of the major issues on the international political agenda, and it must be one of the issues that require emphasis in education (UNESCO 2013; UNEP 2016). To mitigate the impacts of climate change, countries all over the world have acknowledged that ESD, which includes teaching and learning about climate change, is key (UNESCO 2015). ESD is an approach to teaching and learning based on the ideals and principles that underlie sustainability and is applicable to all types, levels and settings of education (Lotz-Sisitka et al. 2017). As such, ESD engages with key issues such as human rights, poverty reduction, sustainable livelihoods and gender equality; and it encourages changes in behaviour that will create a more sustainable future (UNESCO 2015). Climate change education is, therefore, a subject that is well within the ESD agenda (Anderson 2012; UNEP 2016). Climate change education has, however, been differently defined in different contexts. The definition of the concept has been focusing mainly on climate literacy. However,

... Climate change education for sustainable development must be comprehensive and multidisciplinary; it must not only include relevant content knowledge on climate change, environmental and social issues, disaster risk reduction and sustainable consumption and lifestyles, but it should also focus on the institutional environment in which that content is learned to ensure that schools and education systems themselves are climate-proofed and resilient as well as sustainable and green (Anderson 2012: 193 - 194). 
To support the quote above, UNESCO (2013) notes that education is a powerful tool for developing people's knowledge and skills on how to address climate change. Climate change education helps learners understand the impacts of climate change and empowers them on how to adopt appropriate actions to more sustainable lifestyles (UNESCO 2015; UNEP 2016). Countries globally have, therefore, put in place policies that promote climate change education. Countries in the world have also signed up to different climate change conventions and have recently put in place interventions to combat climate change and its impacts through mainstreaming it in the education systems (Boyes et al. 2009; Anderson 2012). However, despite the efforts made to integrate climate change into the education systems of various countries, its implementation has not been successful as planned (Lorenzonia, Nicholson-Coleb \& Whitmarsh 2007; Bangay \& Blum 2010; Anyanwu et al. 2015; Dlamini 2016). Lorenzonia et al. (2007) conducted research on barriers perceived to be engaging with climate change among the United Kingdom public and the policy implications. They found that there was still a need for education that will result in a radical change in values, behaviour and institutions towards a paradigm of lower consumption involving genuine political and widespread social commitment, including at the individual level. However, Bangay and Blum (2010) noted in their research that there is still a need to pay attention to educational approaches that empower people of all ages to deal with the uncertain environmental concerns such as climate change.

Generally a great deal of effort has been devoted to mainstream ESD in the education systems in southern Africa. There has also been much research done on ESD mainstreaming in the southern African context. Some of the research has focused on ESD integration in the school curricula - across different subjects (Tshiningayamwe 2011; Lotz-Sisitka et al. 2017). Some of the research focused particularly on the uptake of ESD in the Geography curriculum (Simasiku 2012; Anyanwu et al. 2015; Dlamini 2016; Zokka 2016; Dube 2017). All these research studies found that there are major challenges in the implementation of ESD content in the school context. These relate to contextual issues and structural constraints within schools (Lotz-Sisitka et al. 2017). Writing in the Zambian context, Shumba and Kampamba (2013) and Namafe and Muchanga (2017) found that a lack of resources, a lack of teachers' knowledge and appropriate approaches as some of the challenges to ESD implementation in the modern schooling system. 


\section{Climate Change Education in the Namibia Context}

Namibia's vulnerable climate change includes an increase in sea-level, droughts, floods, and possibly downwelling in the Atlantic Ocean (Namibia Ministry of Environment and Tourism 2011). This has been integrated in the country's education agenda. Integration of environmental sustainability and climate change issues in Namibia is guided by Article 95 (I) of the Constitution, which calls for active promotion and maintenance of the welfare of its people by adopting policies that are aimed at the maintenance of ecosystems, essential ecological processes and biological diversity of Namibia and sustainable utilisation of living natural resources (Office of the President 2004). Out of Article 95, the Green Plan and Vision 2030 were developed. These plans aim to create a national common vision for sustainable development (Namibia Ministry of Education 2009). Namibia's Vision 2030 describes the kind of society that Namibia should become by the year 2030 . The Vision 2030 document asserts that one of the threats to reaching the 2030 target is the adverse impacts of global atmospheric change (Namibia Ministry of Education 2009). In Vision 2030, the adverse impact of global atmospheric change, climate change and its linkages to water management, food and human health is noted. Namibia's Vision 2030 has challenged and put forward an agenda for education that aims to move Namibia from a heavy industry-based economy to a knowledge-based economy (Namibia Ministry of Education 2009). Climate change education can provide an important platform in Namibia's quest to shift from a heavy industry-based economy to a knowledgebased economy. It also provides awareness and training indispensable to regulating ecological, social or economic systems in response to climate change impacts (Namibia Ministry of Environment and Tourism 2011). Awareness provides the will to act on climate change, while training provides skills, which are the means of achieving a cutback in the alteration of global temperatures and ecosystems (Urquhart et al. 2014).

Furthermore, the Namibian Government ratified the international conventions that have a bearing on climate change education. Those include the United Nations Framework Convention on Climate Change (UNFCC), which aims to stabilise greenhouse gas concentrations in the atmosphere at a level that would prevent dangerous anthropogenic interference with the climate system (Fröhlich 2006). As a result of the above, the Namibian Government has put in place a Climate Change Policy, taking into account the constitution, 
international conventions, regional policies and protocols. The aim of the climate change policy for Namibia is to ensure that Namibia strives for excellence in addressing climate change, by responding in a timely, effective and appropriate manner, via exploring adaptation and mitigation approaches relevant to different sectors at local, regional and national level, in order to improve the quality of life of its citizens (Namibia Ministry of Environment and Tourism 2011). The climate change policy for Namibia has identified mainstreaming of climate change into national development plans and the education environment as a key principle (Namibia Ministry of Environment and Tourism 2011). This principle is important in all formal and non-formal sectors of education. This is with recognition that education is important to mitigating the impacts of climate change in the country (Urquhart et al. 2014). The cross-cutting issues for adaptation and mitigating climate change have been integrated in the country's various educational strategies and plans. The different strategies and plans on climate change also highlight the need to building institutional capacity and research.

As a result of the above, the National Institute for Educational Development (NIED), which is the curriculum development institution in Namibia, has made great strides to infuse environmental themes in basic education systems. The Namibian basic education system is structured in four phases. These are: Early Childhood and Pre-primary education (Grade 0) and Lower Primary education (Grades 1 - 4); Upper Primary education (Grades 4 - 7); Junior Secondary education (Grades 8 - 10), and Senior Secondary education (Grades 11 - 12) (Namibia Ministry of Education 2009). The focus of this paper is Geography, a subject offered in the Junior and Senior Secondary phase (Grade 8 - 12). Because of its complexity (Oversby 2015), the integration of environmental learning is a cross-curricular theme across all phases of the Namibian school systems, across the different subject discipline (Namibia Ministry of Education 2009). Enviroteach was one of the projects that spearheaded mainstreaming of environment and sustainability issues in the Namibian basic education system (Enviroteach 1995). The project received substantial financial support from the Swedish International Development and Co-operation Agency (SIDA) within the agreement of the then Namibia's Ministry of Education, Arts and Culture and the Ministry of Higher Education, Vocational Training, Science and Technology. This support was used to train teachers on how to integrate environment and sustainability issues in teaching and learning, and to develop manuals for teachers on environment and sustain- 
ability (Enviroteach 1995). Another project that supported the integration of environment and sustainability issues in the basic education system was Support Environmental Education in Namibia (SEEN), also supported by SIDA. SEEN assisted the Ministry of Basic Education, Arts and Culture, with the integration of environment and sustainability processes through curriculum development, professional development, and development of teaching and learning materials (SEEN 2005). In terms of Namibian higher education curriculum, there are no specific or stand-alone courses on climate change. Climate change topics are integrated in various environment-related modules such as Agriculture and Environmental Sciences, Sciences, Law, Geography and Environmental Studies, Environmental Management and Conservation Biology (Nhamo \& Shava 2014; Urquhart et al. 2014). These arguably have an impact on teachers' pedagogical content for ESD.

\section{Pedagogical Content Knowledge (PCK)}

Shulman (1986) was the first researcher to describe a knowledge base for teachers or to answer the question: what is it that teachers need to know? Shulman (2004) articulated a framework for teacher knowledge base that comprises four domains, namely: content knowledge, general pedagogical knowledge, context knowledge and pedagogical content knowledge. Content knowledge is the knowledge of the subject content (i.e. climate change content) that needs to be taught (Shulman 2004). He argued that it is important for teachers to obtain deep understanding of the fundamental concepts in their disciplines, and not merely having a huge collection of facts of the subject. It is this understanding of fundamental concepts and how these concepts are related and organised that enables teachers to use their subject matter knowledge for teaching (Shulman 2004). General pedagogical knowledge includes knowledge of classroom organisation and management, different teaching strategies or methods, assessment strategies as well as understanding classroom communication and discourses (Shulman 2004). Context knowledge is knowing about the background of the learners, knowing the organisational culture of the school, the governance and financing of the school district, to the character of communities and cultures (Shulman 2004). PCK is understood as the way in which the teacher recontextualises the content knowledge so that it can be understood by the learner (Shulman 2004). Shalem 
and Pendlebury (2010) note that PCK is an overlap between subject knowledge and pedagogic knowledge.

Thomas (2013) noted that other components of teacher knowledge discussed by Shulman $(1986 ; 2004)$ that are essential for excellent teaching were subject matter knowledge, curricular knowledge, knowledge of learners and their characteristics, and knowledge of education ends, purposes, and values. Thus from Shulman's initial work and the work of those who have followed him, it is evident that teachers draw on deep disciplinary knowledge, general and personal pedagogical knowledge and PCK. However, Shulman's knowledge domains are largely propositional and he has been critiqued for not taking into account the inter-relationship between theory and practice (Van Driel, Verhoop \& De Vos 1998). He does not engage sufficiently with teachers' practical or professional knowledge, but seems to present a model where different kinds of propositional teacher knowledge simply 'add up to' a good teacher. However, a key concern in the area of climate change education is the relationship between propositional knowledge and practical knowledge (Nhamo \& Shava 2014). Teachers also need conceptual knowledge for teaching which is much more than just subject knowledge (Shulman 2004) as this must be supplemented with innovative delivery mechanisms that can enhance learners' understanding of concepts being taught. Thus, for effective integration of climate change education in the Namibian school Geography curriculum, teachers need a variety of knowledge as presented by Shulman and academics that improved on his work.

\section{Research Design}

The research was an explorative qualitative case study. Qualitative research stresses the socially constructed nature of empirical experiences, the intimate relationship between the researcher and what is studied, and the situational constraints that shape inquiry (Denzin \& Lincoln 2011). Case study methodlogy is significant for learning about environmental learning (Lotz-Sisitka \& Raven 2004) as it allows for researchers such as this author to research environment and sustainability issues in a context such as climate change, and it allows for improving professional practice. The data presented in this paper were collected through semi-structured interviews with four Namibian Secondary school Geography teachers (named T1, T2, T3 and T4). The semi- 
structured interviews were chosen as they allowed the research to probe teachers' perceptions of climate change integration in the Geography curriculum (Denzin \& Lincoln 2011). The Namibian school Geography curriculum documents were analysed on climate change content which served as primary data sources (Harland 2014). The data generated were analysed using Shulman's PCK model (Shulman 1986; 2004). Careful attention was given to ethical issues that confronted the researcher. This includes policies regarding informed consent, confidentiality and anonymity (Harland 2014).

\section{Climate Change Integration into the Namibian School Geography Curriculum}

According to the Namibian Ministry of Education (2008), the Geography syllabus like other syllabi should address cross-curricular issues through geographic perspectives. The cross-curricular issues which have been introduced into the formal curriculum as themes to be dealt with in each subject are: Environmental learning, HIV/AIDS, Education for Human Rights, Population Education, and Information Communication Technology (Namibia Ministry of Education 2009). The aim of the Namibian school Geography curriculum is to enable learners to understand the nature of the following risks and challenges, and to know how they will impact on our society and on the quality of life of our people now and in the future. Those include:

- The challenges and risks we face if we do not care for and manage our natural resources

- The challenges and risks to health caused by pollution, poor sanitation and waste

- The challenges and risks to democracy and social stability caused by inequity and governance that ignores rights and responsibilities

- The challenges and risks we face from globalisation (Namibia Ministry of Education 2008:4).

The above clearly shows that the Namibia Geography curriculum makes provision for teaching environment and sustainability (i.e. climate change) challenges and associated risks. This was reflected in the curriculum analysis done (Namibian Ministry of Education and Culture 2005; Ministry of Edu- 
cation 2008). Topics of the curriculum that are related to climate change include: weather and climate; population studies; urbanisation; production and management; coastal processes and erosion; impact of industries on the environment, e.g. energy/fossil fuels; impact of agricultural system on the environment, e.g. deforestation; impact of tourism on the environment, and population and settlement studies. It was evident from the curriculum analysis that climate change was not a separate topic but was integral to other topics in the Geography curriculum (Namibia Ministry of Education and Culture 2005; Namibia Ministry of Education 2008). This analysis was supported by Geography teachers who stated that efforts have been made to include environment and sustainability aspects in the Geography curriculum. Teachers noted that climate change aspects are integral to other topics in the curriculum. T4 and T3 stated:

T4: Climate change aspects in Geography are covered across the different grades under different topics. For example, in Grade 9 it is covered under the topic of climatology - pollution which releases greenhouse gases in the atmosphere causing global warming, greenhouse gases cause damage to the ozone layer, and in Grade 10 it is covered under the topic of ecology where learners are taught about the dangers of human activities such as desertification, deforestation and how they may contribute to climate change. In Grade 11 and 12, it is covered under the topic of environmental risks and management i.e. global warming, acid rain and deforestation.

T3: Within the school curriculum, climate change is not dealt with as a separate topic, but rather integrated into other topics. Example in Namibia Senior Secondary Certificate (NSSC) Geography Syllabus, Natural Vegetation is a topic exploring the world's biomes and how change has occurred over time due to climate change.

The above statements are an indication that Geography teachers had curricular knowledge. Curricular knowledge includes knowledge of the sequence of topics or concepts to be taught and the materials and resources suitable for a particular topic (Shulman 2004). Teachers note, however, that the amount of climate change content covered in the Namibian school Geography curriculum is inadequate. The Namibian school curriculum was in the process of undergoing a curriculum review. The teachers interviewed observed that even with the curriculum review, the amount of climate change content in the 
Geography curriculum is still the same. They observed that climate change content is lost in the overarching themes. In relation to the amount of climate change aspects in the new Geography curriculum, T2 and T3 revealed:

T2: Climate change is hardly covered in the school curriculum, even with the new curriculum that has been so far implemented in Grade 7 and 8. The Grade 8 syllabus covers topics such as weather and climate, geomorphology and economic geography. But with the current Grade 11 12 curriculum, little is covered in terms of climate change.

T3: The new curriculum does not cover much on climate change, and this is one of the challenges of teaching climate change as teachers are not allowed to teach anything beyond the syllabus. I thus do not teach much of climate change because of the limited syllabus coverage.

The above analysis is worrisome. This resonates with earlier studies done on integration of ESD in the Namibian Geography curriculum (Simasiku 2012; Zokka 2016). Teachers interviewed were aware of the impacts of climate change. They expressed the opinion that the impacts of climate change are visible in their communities, thus noting that the importance of climate change within the Geography curriculum is not questionable. As T1 and T4 said,

T1: The importance of climate change is not questionable as climate change has the power to affect the livelihoods of our communities, thus should be incorporated in the school curriculum.

T4: The importance of climate change especially in the context of Geography education it makes people become aware of its causes, makes people responsible about their daily activities and how these activities contributes to climate change, it allows people to study the trends of climate change and the future prediction, allows people to anticipate any consequences of climate change to their environment and suggest solutions, as well as educate people to minimise pollution.

The above findings resonate with IPCC (2014) and UNEP (2016) reports that noted that impacts of climate change have been evident in the past few decades. Those impacts are also clearly evident in the Namibian context (Namibia 
Ministry of Environment and Tourism 2011). Teachers thus noted that the content of climate change is important for the Namibian school Geography curriculum. These helps equip learners with skills to help combat climate change (Nhamo \& Shava 2014). Education is an essential element of the global response to climate change (Anderson 2012). Teachers also recognised that the Namibian Geography curriculum considered not only the Namibian context; it also covers the global context. T2 observed:

Geography education in the Namibian context has to focus on raising awareness and informing learners about environmental degradation, climate change, species extinction, rising sea levels, excessive or unequal consumption, resource depletion and lack of wellness in our world, and not only as local problems but as a global predicament.

In line with the above observation, there has been a great deal of recognition that environment and sustainability issues are global (IPCC 2014; UNESCO 2015). Learners therefore need to understand the nature of environmental issues, their associated risks and challenges at both local and global level (Hogan 2008). The aim of the Geography curriculum is thus to ensure that learners understand how these risks and challenges can be addressed on a personal, local, national, and global level and how they can play a part in addressing these risks and challenges in their own schools and local communities (Namibia Ministry of Education 2008; 2009). To help empower learners understand the global impacts of climate change, the curriculum covers topics that allows learners to understand climate change impacts at both national and global level (Namibia Ministry of Education 2008). For example, natural vegetation is a topic that is covered in the curriculum. The topic aims at enhancing learners' knowledge and skills on exploring the world's biomes and the impacts of climate change on these biomes.

\section{Challenges for Integrating Climate Change Content into the Namibian School Geography Curriculum \\ a) Geography Teachers' Pedagogical Content Knowledge on Climate Change}

Data from the interviews reveals that Geography teachers in Namibia were not 
prepared to teach climate change aspects in the Geography curriculum. This was noted by $\mathrm{T} 3$ and T4 who said:

T3: I don't think teachers are well prepared to teach climate change in the Geography curriculum as little emphasis has been done on climate change. Teachers are not trained and some are probably not aware to what extent climate change can be taught. There are few teacher workshops given on Geography and even when they are offered, a lot of times, the people who facilitate these workshops only focus on how teachers can make passes and do not necessarily focus on how teachers can provide life changing education to learners.

T4: Teachers are not prepared to teach climate change as a topic but rather prepared to teach topics that are directly related to Environmental issues, climate change is indirectly related to that. Very few materials exist to support teaching and learning in the classroom about climate change, especially in remote rural schools that don't have access to electronic content or internet; however, few printed materials are available.

Even though climate change aspects have been integrated in the Geography curriculum, teachers were not well prepared to teach climate change content (Nhamo \& Shava 2014). Teachers were trained as Geography teachers on the different topics in the curriculum, but they lacked the content knowledge of climate change (Zokka 2016). Teachers thus expressed in their interviews that they experience conceptual difficulties regarding teaching climate change. This resonates with Dube (2012; 2017; Anyanwu et al., 2015), who observed that in South Africa, Geography teachers lack conceptual understating on ESD. The two quotes from T3 and T4 above demonstrate the lack of teachers' content knowledge and knowledge of facts and concepts on climate change (Shulman 2004). Similar to Shulman, Ball et al. (2008) argue that content knowledge is foundational to teachers' competency. This implies that Geography teachers lacked the competency to teach climate change content in the curriculum (Wiek, Wathycombe \& Redman 2011). Wiek et al. (2011) argue that teachers need to have different competencies for ESD. This was is in line with Hermans (2016), who noted that Geography teachers need different competencies to teach climate change topics. In terms of the Geography curriculum, different competencies will enable teachers to be able to assess 
learners inquiry skills related to climate change. Those include questions that allow learners to organise and analyse information and to make judgments based on the information gathered (Namibia Ministry of Education 2008). This is because the subject matter related to climate change is complex and contested (Corney \& Reid 2007). This was noted by T2:

Climate change concepts are difficult to understand, some learners are unable to use proper language. There is too much content to teach and it may require a lot of time to cover, it needs a lot of visualisation and technology to understand and some schools do not have such facilities.

It is thus evident that Geography teachers expressed difficulties in teaching aspects of climate change in the curriculum. This was also demonstrated by their lack of pedagogical content knowledge to ESD. Dube (2012) suggested that ESD can benefit from Geography because of the approaches used to teach the content. Those include simulations, fieldwork, inquiry-based and problemsolving approaches to learning. Resonating with this, the Namibian Geography curriculum suggests the use of issue-based and inquiry-based approaches, including fieldwork activities (Namibia Ministry of Education 2008). Issuebased approaches enable teachers to focus on social and natural issues in local contexts (Simasiku 2012), whereas inquiry-based methods enable learners to think critically and to solve environmental issues in local contexts (O’Donoghue 2015). Despite the importance of inquiry-based and issues-based approaches to geographers, it emerged from the interview with the teachers that they did not use inquiry-based approaches in their teaching of climate change. This resonates with Simasiku (2012) and Zokka (2016), who observed that in Namibia, despite the fact that pedagogical approaches to environmental learning in Geography provides meaningful learning experiences to learners in the formal school context, they are rarely used. Their investigations confirmed that a number of structural and pedagogical factors need to be addressed to ensure the effective implementation of enquiry-based fieldwork in the Namibian Secondary school curriculum. Teachers need to engage learners in the field work/field excursion, this could be exposure to impacts of climate change in the local contexts (Dube 2012; 2017).

Even though inquiry-based and issues-based approaches were not commonly used to teach climate change content in the Geography curriculum, teachers were aware that the learner-centred education framework requires 
engaging learners in teaching and learning (Namibia Ministry of Education 2009). Learner-centred education is a Namibian conceptual policy framework, which encourages learner participation and involvement in pedagogy. With regard to climate change, learner-centred education will promote critical thinking and problem solving skills in learners (Namibia Ministry of Education 2008). Learner-centred education sees a learner as an active, inquisitive human being, eager to learn, to investigate and make sense of his/her surrounding world (Namibia Ministry of Education 2009). To encourage learners' participation in learning, the teachers thus noted that they use a lot of discussions to teach aspects of climate change in the curriculum. As T1 revealed in the interview:

Using learners' experiences in the discussions on climate change, boils down to learner-centred education, the learners have ideas, it's not like they don't know what is going out in nature, if one have to look at climate change ... they can also learn from each other as they come from various parts of the country. For example, a learner coming from the coast will share the impacts of climate change at the sea, while the learner from the north will talk about drought and floods....

\section{b) Geography Teachers' Context Knowledge on Climate Change}

Data from the interviews reveals that Geography teachers in Namibia lack the context knowledge on climate change. This was noted by T3 and T4 who said:

T3: For instance, we do not have enough knowledge when it come to examples of topics like impacts of tourism on the environment, or the use of modern technology, for example what type of modern technology they use to increase food production, learners need to know this knowledge on how they use tractors for ploughing maize and millet.

T4: I would like to go for local ... for instance I cannot give an example of the effect of climate change on the Etosha Cuvelai Basin when learners do not know what the Etosha Cuvelai Basin is like... that is why they say we should use our natural environment as a proper example in our teaching 
because if, for example, you are telling the learners about proper housing and they have never seen a proper house, it will be difficult for them to understand. I would like to give examples of things that learners are familiar with.

In support of the above observation, Hogan (2008) and Shulman (1986; 2004) highlights the use of everyday contexts and experience for meaningful learning. Hogan (2008) argues that using everyday contexts involve learners in classroom activities that increase learners' confidence in solving local issues. This allows learners to share responsibilities and to take control of their own learning. This is in line with the learner-centered approach being advocated for in Namibia. In relation to the Namibian learner-centred policy framework (Namibia Ministry of Education 2009), teachers also acknowledged in the interviews that they use local contexts to teach aspects of climate change.

\section{c) Learners' Knowledge on Climate Change}

Despite the importance of engaging learners in teaching and learning, teachers recognised that learners lack knowledge on climate change as a challenge to integrating climate change in the Geography curriculum. As T1 and T2 observed:

T1: Learners struggle to understand this knowledge because they are not exposed, learners need to be exposed more to climate change through television and radio programmes. There is a need to discuss climate change topics in the newspapers, as well as more practical activities for learners on climate change.

T2: Climate change concepts are difficult to understand, some learners are unable to use proper language and do not have an idea of what climate change is, and that climate change is happening...

Resonating with the above observations and in addition to teacher context knowledge, Shulman (1986; 2004) argues that learners' general content knowledge is key to effective teaching and learning. This is central to the learnercentred policy framework in Namibia (Namibia Ministry of Education 2009). 
The learner-centred education is devoted to encouraging learners to solve their own problems, to promote critical thinking, practical work and self-confidence. Central to learner-centred education is the assumption that knowledge is created by individuals through a process of making sense that involves establishing a link between prior knowledge and new information. The process happens both individually and socially by constructing, de-constructing and reconstructing knowledge (Namibia Ministry of Education 2009).

\section{d) Other Challenges for Integrating Climate Change into the Namibian School Geography Curriculum}

In addition to the above, teachers mentioned other challenges for integrating climate change content in the Namibian school Geography curriculum. Those includes the lack of teachers ability to use global approach to teaching climate change, lack of access to visual teaching aids such as videos on local and global climate change issues, lack of textbooks, and access to technology, lack of support for teachers on climate change and overloaded Geography curriculum. Some of these challenges were revealed by $\mathrm{T} 2, \mathrm{~T} 3$ and $\mathrm{T} 4$ as indicated below:

T2: Issues of climate change are not only local, they are global, however a lot of teachers have a little understanding on how to use global approach to teaching to raise awareness and to inform learners about environmental degradation, climate change, biodiversity loss, melting of ice caps, unsustainable consumption, resource depletion and lack of environmental wellness in our world.

T3: Some schools have the necessary resources to teach but most schools have no facilities such as overhead projectors, teaching aids, visualizations or internet, this makes it difficult to play videos and expose learners to local climate change issues....

T4: I am not aware of any existing support offered to Geography teachers to aid effective teaching of the climate change content in the Geography curriculum .... Climate change concepts are difficult to understand and there is too much content in the syllabus which requires a lot of time to teach thus do not give teachers time to do research on climate change topics. 
The above observations have been observed by (Simasiku 2012; Nhamo \& Shava 2014; Anyanwu et al., 2015; Dlamini 2016; Zokka 2016). In relation to the challenges for teaching climate change aspects in theNamibian school Geography curriculum, teachers thus recommended the following:

- Adopting an interactive teaching and learning strategy and engaging leaners in the field work/field excursion;

- Providing quality and relevant teaching materials;

- Frequent continuous professional development activities focusing on climate change; and

- Implementing specific strategies and action plans for climate change education.

\section{Conclusions and Recommendations}

The paper has explored climate change integration in the Namibian school Geography curriculum. It is evident that although the Namibian Geography curriculum has integrated climate change content, it is inadequate. It is further evident that there are various challenges hampering its effective curriculum integration. Evidence shows that the complex nature of climate change concepts hinders its effective integration. Other constraints include a lack of teachers' pedagogical content knowledge, insufficient quality teaching resources on climate change, learners' poor language skills and an overloaded curriculum.

To help take action to combat climate change and its impacts, there is a need for the Namibian Ministry of Basic Education, Arts and Culture to review the current Geography curriculum to include more climate change content. In collaboration with other stakeholders, the Ministry should provide professional development on climate change education for in-service teachers. This is to enhance Geography teachers' pedagogical content knowledge and understanding of climate change, such that they will be able to integrate topics on climate change in schools. There is also a need for teacher education institutions in Namibia to integrate climate change content in teacher education curricula. The paper further recommends provision of sufficient quality teaching materials on climate change. This could be from the Ministry of Basic Education, Arts and Culture and other stakeholders in education. The 
Namibian government and the non-governmental sectors including the media should collectively strive to promote public awareness on climate change and its impacts. The media should be educated on how to cover relevant local articles on climate change. In conclusion, this paper calls for more research on professional support of Geography teachers on climate change in Namibia. Furthermore, with the implementation of the Sustainable Development Goals, there is a need to explore the nexus between Sustainable Development Goal 13 and teachers' pedagogical knowledge within Geography education.

\section{References}

Anderson, A. 2012. Climate Change Education for Mitigation and Adaptation. Journal of Education for Sustainable Development 6, 2: 191 - 206.

https://doi.org/10.1177/0973408212475199

Anyanwu, R., L. le Grange \& P. Beets 2015. Climate Change Science: The Literacy of Geography Teachers in the Western Cape Province, South Africa. South African Journal of Education 35, 3: 1 - 9.

https://doi.org/10.15700/saje.v35n3a1160

Ball, D.L., M.H. Thames \& G. Phelps 2008. Content Knowledge for Teaching: What Makes it Special? Journal of Teacher Education 59, 5: 389 - 407.

https://doi.org/10.1177/0022487108324554

Bangay, C. \& N. Blum 2010. Education Responses to Climate Change and

Quality: Two Parts of the Same Agenda? International Journal of Educational Development 30, 4: 359 - 368.

https://doi.org/10.1016/j.ijedudev.2009.11.011

Boyes, E., K.R. Skamp \& M. Stanisstreet 2009. Global Warming Responses at the Primary Secondary Interface: Potential Effectiveness of Education. Australian Journal of Environmental Education 25: 31 - 44.

https://doi.org/10.1017/S0814062600000380

Corney, G. \& A. Reid 2007. Student Teachers' Learning about Subject Matter and Pedagogy in Education for Sustainable Development. Environment Education Research 13, 1: 33 - 54.

https://doi.org/10.1080/13504620601122632

Denzin, N.K. \& Y.S. Lincoln 2011. The Sage Handbook of Qualitative Research. Thousand Oaks: Sage Publishers.

Dlamini, M.N. 2016. Understanding and Teaching Climate Change in the 
Secondary Education Curriculum in Swaziland. Unpublished doctoral thesis, University of Pretoria, Pretoria.

Dube, C. 2012. Implementing Education for Sustainable Development: The Role of Geography in South African Secondary Schools. Unpublished doctoral thesis, University of Stellenbosch, South Africa.

https://doi.org/10.1007/978-3-319-45989-9_7

Dube, C. 2017. The Uptake of Education for Sustainable Development in Geography Curricula in South African Secondary Schools. In LotzSisitka, H., O. Shumba, J. Lupele \& D. Wilmot (eds.): Learning Today for Tomorrow: Education for Sustainable Development and Schools in Africa. Springer Publisher.

Ekpoh, I.J. 2009. Climate, Society and Environment. Calabar: St. Paul Publishing Co.

Enviroteach 1995. Investigating of Opportunities for the Implementation of Enviroteach Programmes in Namibia Colleges of Education. Windhoek: DRFN.

Fröhlich, G. 2006. Namibian Environmental Education Certificate. Module 1. Study Guide. Windhoek: Center for Open and Lifelong Learning, Polytechnic of Namibia.

Harland, T. 2014. Learning about Case Study Methodology to Research Higher Education. Higher Education Research and Development 6: 1113 - 1122. https://doi.org/10.1080/07294360.2014.911253

Hogan, R. 2008. Contextualizing Formal Education for Improved Relevance:

A Case from the Rufiji Wetlands, Tanzania. Southern African Journal of Environmental Education 25, 44 - 56.

Hermans, M. 2016. Geography Teachers and Climate Change: Emotions about Consequences, Coping Strategies, and Views on Mitigation. International Journal of Environmental \& Science Education 11, 4: 389 - 408.

Intergovernmental Panel on Climate Change (IPCC). 2014. The IPCC's Fifth Assessment Report: What's in it for Africa? Kenya: Nairobi, Overseas Development Institute and Climate and Development Knowledge Network. Available at: https://cdkn.org/resource/highlights-africaar5/?loclang=en gb. (Accessed on 26 August 2017).

Lorenzonia, I., S. Nicholson-Coleb \& L. Whitmarsh 2007. Barriers Perceived to Engaging with Climate Change among the UK Public and their Policy Implications. Global Environmental Change 17, 4: 445 - 459. https://doi.org/10.1016/j.gloenvcha.2007.01.004 
Integration of Climate Change into the Namibian Geography Curriculum

Lotz-Sisitka, H., O. Shumba, J. Lupele \& D. Wilmot (eds.) 2017. Learning Today for Tomorrow: Education for Sustainable Development and Schools in Africa. Springer Publisher.

https://doi.org/10.1007/978-3-319-45989-9

Lotz-Sisitka, H. \& Raven, G. 2004. Learning through Cases: Adopting a Nested Approach to Case Study Work in the Gold Fields Participatory Course Initiative. Environmental Education Research 1: 67 - 87.

https://doi.org/10.1080/1350462032000173715

Namibia Ministry of Education and Culture 2005. Namibia Senior Secondary Certificate (NSSCO): Geography Syllabus (Grade 11 - 12). Okahandja: National Institute for Educational Development (NIED).

Namibia Ministry of Education 2008. Junior Secondary Phase, Geography Syllabus Grade 8 - 10. Okahandja: National Institute for Educational Development (NIED).

Namibia Ministry of Education 2009. The National Curriculum for Basic Education. Okahandja: National Institute for Educational Development (NIED).

Namibia Ministry of Environment and Tourism 2011. National Policy on Climate Change for Namibia. Namibia: Windhoek.

Namefe, C. \& M. Muchanga 2017. The Relation of Mainstreaming Environmental Education to the Modern Schooling System in Zambia. In Lotz-Sisitka, H., O. Shumba, J. Lupele \& D. Wilmot (eds.): Learning Today for Tomorrow: Education for Sustainable Development and Schools in Africa. Springer Publishers.

https://doi.org/10.1007/978-3-319-45989-9 4

Nhamo, G. \& S. Shava (eds.) 2014. Climate Change Education in the SADC School Curriculum. Pretoria: Africa Institute of South Africa.

O'Donoghue, R. 2015. Environment and Sustainability Education: Quality Teaching in Relation to Human Conduct and the Common Good. B.Ed. Honours Environmental Education Elective. Grahamstown: Environmental Learning and Research Centre, Rhodes University.

Office of the President. 2004. Namibia Vision 2030: A Policy Framework for Long-term National Development. Windhoek: Government Printers.

Oversby, J. 2015. Teachers' Learning about Climate Change Education. Social and Behavioral Sciences 167: 23 - 27.

https://doi.org/10.1016/j.sbspro.2014.12.637

Ozor, H. 2006. Climate Change and its Impacts on Development. CUP. 
Shalem, Y. \& S. Pendlebury 2010. Retrieving Teaching: Critical Issues in Curriculum, Pedagogy and Learning. South Africa: Juta and Company. Shulman, L. 1986. Those who Understand: Knowledge Growth in Teaching. Educational Researcher 15, 2: 4 - 14.

https://doi.org/10.3102/0013189X015002004

Shulman, L. 2004. Teaching as Community Property. Essays on Higher Education. USA: Jossey Bass Wiley.

Shumba, O. \& R. Kampamba 2013. Mainstreaming ESD into Science Teacher Education Courses: A Case for ESD Pedagogical Content Knowledge and Learning as Connection. Southern African Journal of Environmental Education 29, 151 - 166.

Simasiku, F. 2012. An Investigation of How Inquiry-based Fieldwork Develops Action Competence in Grade 112 Geography: A Namibian Case Study. Unpublished master's thesis, Rhodes University, Grahamstown, South Africa.

Support Environmental Education in Namibia 2005. Education for Sustainable Development in Namibia: The Experience of SEEN: Past Responses and Future Directions. Windhoek.

Thomas, M. 2013. Teachers' Beliefs about Classroom Teaching - Teachers' Knowledge and Teaching Approaches. Social and Behavioral Sciences 89, 31 - 39.

https://doi.org/10.1016/j.sbspro.2013.08.805

Tshiningayamwe, S.A.N. 2011. Implementation of Environmental Learning in the NSSC Biology Curriculum Component: A Case Study of Namibia. Unpublished Master's Thesis, Rhodes University, Grahamstown, South Africa.

UNEP 2016. Summary of the Sixth Global Environment Outlook GEO-6 Regional Assessment: Key Findings and Policy Messages. Kenya: Nairobi.

UNESCO 2013. Climate Change in the Classroom. Paris: France.

UNESCO 2015. Education for All 2000 - 2015: Achievements and Challenges. Paris: France.

Urquhart, P., H. Lotz-Sisitka, B. Kruger \& J. Naudé 2014. Strengthening University Contributions to Climate Compatible Development in southern Africa. Knowledge Co-production Framework. South Africa: SARUA.

Van Driel, J. H., N. Verloop \& W. de Vos 1998. Developing Science Teachers' Pedagogical Content Knowledge. Journal of Research in Science 35, 6: 
Integration of Climate Change into the Namibian Geography Curriculum

$673-695$.

https://doi.org/10.1002/(SICI)1098-2736(199808)35:6<673::AIDTEA5>3.0.CO;2-J

Wiek, A., L. Wathycombe \& C.L. Redman 2011. Key Competencies in Sustainability: A Reference Framework for Academic Program Development. Sustainable Science 6, 2: 203 - 218. https://doi.org/10.1007/s11625-011-0132-6

Zokka, H.K. 2016. Presentation and Representation of Environmental Problems and Problem-solving Methods and Processes in the Grade 10 Geography Syllabus: A Namibian Case Study. Unpublished Master's thesis, Rhodes University, Grahamstown, South Africa.

Sirkka A.N. Tshiningayamwe International University of Management (IUM)

Namibia sirkka.ts@gmail.com 